\title{
NOTAS SISTÉMICO-FAMILIARES \\ SOBRE LAS VULNERABILIDADES: LOS CUENTOS DE NUESTRA FRÁGIL FORTALEZA
}

\author{
Carolina Fernández Acuña ${ }^{1}$
}

\section{Palabras Preliminares}

"Las personas adultas aman las cifras. Cuando les habláis de un nuevo amigo, no os interrogan jamás sobre lo esencial. Jamás os dicen: “¿Cómo es el timbre de voz? ¿Cuáles son los juegos que prefiere? ¿Colecciona mariposas?”. En cambio, os preguntan: “¿Qué edad tiene? ¿Cuántos hermanos tiene? ¿Cuánto pesa? ¿Cuánto gana su padre? Solo entonces creerán conocerle... Pero, claro está, nosotros que comprendemos la vida, nos burlamos de los números. Hubiera deseado comenzar esta historia a la manera de los cuentos de hadas. Hubiera deseado decir: "Había una vez un principito que habitaba un planeta a penas más grande que él y tenía necesidad de un amigo." ("El Principito"; Antoine De Saint - Exupéry, Ed. Gallimard, Francia, 1951)

\section{Resumen}

En el texto a continuación se desarrollarán algunos conceptos clave de la comprensión sistémica de la organización relacional familiar, que permitan al lector situarse como observador participante del sistema familiar, a la vez que comprender sistémicamente aquello de lo que participa. Una vez que se establece esa posición, se da paso a elaborar una breve comprensión de las vulnerabilidades a la luz de situaciones clínicas. Se concluye con una apertura a la visión crítica de estos conceptos y a la construcción constante de usos clínicos en los que prime la responsabilidad, el respeto a la diversidad y a los derechos humanos.

$1 \quad$ Doctoranda en Psicología - Universidad de Flores, Bs.As. Argentina. Mg. Terapia Familiar Sistémica Psicóloga - Terapeuta Familiar. Docente Escuela de Psicología de la Facultad de Ciencias de la Salud, Universidad Arturo Prat. Victoria - Chile. Correo electrónico cferacuna@gmail.com. 
Palabras clave: terapia sistémica, recursos familiares, estructura, funciones, vulnerabilidad.

\section{Abstract}

In the following text some key concepts of the systemic understanding of the family relational organization will be developed, which allow the reader to situate himself as a participating observer of the family system, at the same time as systemically understanding what he participates in. Once that position is established, a brief understanding of vulnerabilities in light of clinical situations is developed. It concludes with an openness to the critical vision of these concepts and to the constant construction of clinical uses in which responsibility, respect for diversity and human rights prevail.

Keywords: systemic therapy, family resources, structure, functions, vulnerability.

\section{Palabras preliminares}

Muchas veces, los estudiantes y trabajadores de salud mental, decimos de nosotros mismos que nuestras disciplinas nos permiten conocer y comprender a las personas. En este proceso de conocer, cada quién "moldea su anteojo", de acuerdo con las premisas de su teoría y de aquello que considera más importante. Puestos en esta posición, resaltamos, entonces, el hecho de que nos encontraremos con múltiples miradas, evaluaciones y propuestas para realizar esta tarea de conocer y comprender. En nuestras conversaciones con las familias y las personas, los terapeutas sistémicos nos disponemos a observar patrones de comportamiento que emergen en esquemas relacionales; escuchamos relatos con los que cada quién habla de lo que le pasa y de quién es, a la vez que manifiesta lo que cree, siente y anhela, nos cuenta lo que teme, lo que cree que es correcto, lo que otros le han dicho que debe ser. Creemos que en cada interacción surge algo de lo que somos, que se presenta de cierto modo a propósito de esa interacción específica e intentamos identificar los elementos que componen ese esquema de manera estable, así como aquellos que son susceptibles de cambiar. A propósito, entonces, de la manera en que observamos es que desarrollamos una noción de experiencia en la que confluyen distintos elementos personales, familiares y sociales. Algunos de esos elementos 
resultarán favorecedores para la salud y el desarrollo, otros no; mas todos ellos danzarán simultáneamente en cada vivencia que experimentamos. Desde esta perspectiva, comprenderemos que conocer a los otros supone integrar un cúmulo de información diversa, que escuchamos, que vemos, que proviene de fuentes institucionales, que viene de nuestro conocimiento disciplinario y transdisciplinario, información toda que cobrará un sentido específico en cada situación, en cada persona, en cada familia, sentido que ellos han construido y reconstruirán con nosotros en los procesos de acompañamiento e intervención. ¿Qué sentido tiene recordar estas premisas básicas de la comprensión sistémica? Coloquialmente, entendemos vulnerabilidad como la posibilidad de resultar dañado, herido, ya sea física o moralmente, a propósito de algo concreto; sin embargo, las premisas sistémicas nos invitan a abrir el zoom de nuestro lente de observación para hablar no sólo de la posibilidad de resultar dañado, sino también de las múltiples maneras en que enfrentamos con éxito situaciones adversas y utilizamos en ellas un sinfín de recursos que diversifican nuestras realidades y dan significado a lo que vivimos. Es así, entonces, que nuestra mirada de los otros (y de nosotros mismos) incorporará una noción flexible de los conceptos que conocemos, nos permitirá buscar "factores de riesgo", "elementos de vulnerabilidad", mas buscaremos también todos aquellos elementos con los cuales las personas viven sus vidas significativamente y transforman, de maneras múltiples, y (muchas veces sorprendentes), el mundo en que viven, sus relaciones y sentidos. En este texto, revisaremos algunos conceptos clave de la comprensión terapéutica sistémica. En función de ellos, plantearemos algunas propuestas específicas con las que, actualmente, trabajamos para comprender las vulnerabilidades, identificar y resaltar los recursos y acompañar los caminos de cambio y recuperación. 


\section{"Una escena cotidiana": conceptos generales de la visión sistémico-familiar}

\section{Estructura familiar: líneas gruesas para la construcción de las familias}

Uno de los factores distintivos de la terapia familiar sistémica es la focalización en la familia como unidad mínima de análisis. Ya en los inicios, Bateson (1969), planteaba una comprensión particular de la vida psíquica, entendiéndola como un resultado que integra la manera en que, individualmente, organizamos la experiencia relacional, y sintetizaba diciendo: "La unidad de supervivencia es el organismo en el ambiente". Desde esta mirada, todo lo observable podía constituirse como sistema, siempre que cumpliese con sus características esenciales, a saber: una conjunción de elementos cuyo funcionamiento se sustenta, por un lado en la presencia de la energía que lo mueve, los intercambios, las fuerzas, los móviles, las tensiones que le permiten existir como tal; y, por el otro, la circulación de informaciones y significaciones mismas, que permite el desarrollo, la regulación y el equilibro del sistema (Watzlawick, Weakland, \& Fish, 1974).

Comprendiendo que nuestra experiencia no sucede en el vacío, Salvador Minuchin (1977) plantea también una comprensión interaccional de la vida psíquica y se focaliza en la relación de la persona y sus contextos. Desde ahí, delimita un contorno inicial para leer nuestras relaciones y se centra en la familia, definiendo la estructura familiar como: "el conjunto invisible de demandas funcionales que organizan los modos en que interactúan los miembros, es decir, que el sistema familiar se expresará a través de pautas transaccionales cuyo funcionamiento se da con base en reglas acerca de quiénes son los que actúan, con quién y de qué forma". Desde esta mirada, la familia se constituye como nuestra primera realidad vincular y cultural, que tiene como objetivos básicos ofrecer protección (global, socioafectiva) y desarrollo a sus miembros, a la vez que transmite las pautas de la cultura. La familia debe permitir a los miembros configurar un sentido de pertenencia y construir un sentido de identidad. 
Si consideramos lo anterior, la familia emerge como una realidad sistémica que se distingue de otros sistemas por sus elementos característicos, siguiendo a Minuchin (op.cit. 1977), estos son:

Subsistemas: Al decir que la familia es un sistema, decimos también que comparte los elementos constituyentes de todo sistema; uno de ellos es el reconocimiento de que cada unidad constituyente de él puede, a su vez, comprenderse como un sistema, sin por ello perder su cualidad de elemento constituyente y sin amenazar la identidad del sistema que la contiene. Llamaremos subsistemas a las unidades vinculares que, por su rol y cualificación cultural, se distinguirán de los demás, pero los necesitarán para existir y delimitarse; los subsistemas familiares más definidos en nuestra cultura (occidente) son el subsistema parental (ejecutivo, dirección, organiza la transmisión cultural y el desarrollo socio afectivo), el subsistema filial (receptor, transformador de modelos, integrador de información extra sistema) y el subsistema fraterno (hermano/as, semejanza en edad y status generacional).

Límites: Conocemos de la estructura familiar y sus subsistemas a propósito de que entre ellos identificamos límites, vale decir, reglas que diferencian los roles ejercidos en la familia, que permiten la conformación de identidad personal y familiar, y que sustentan las líneas a través de las cuales se proyecta el desarrollo de los miembros. La construcción de los límites varía en cada familia y cultura. Sin embargo, se identifica como saludable una disposición de límites lo bastante clara como para que cada miembro conozca tanto su rol como el de los otros, y que permita organizar la interacción en un contexto de protección, respeto y desarrollo identitario; y lo bastante flexible como para que permita la exploración progresiva del ejercicio de los roles y el contacto permanente entre los miembros de la familia. La manera en que se construyen estos límites nos permite situar a las familias en un continuo comprensivo: desde aquellas en que se establecen unos límites inadecuadamente rígidos, hasta aquellas en que los límites son difusos y poco sustentadores de la estructura familiar.

Jerarquía: Supone la manera en que la organización de la familia permite el ejercicio de poder a cada miembro, permite diferenciar los roles, establecer líneas de organización y soporta la diferenciación generacional. 
Alianza: Supone una afinidad positiva específica entre dos o más miembros del sistema, a propósito de un interés, empresa particular, actitud o valores concretos en común. Las alianzas son frecuentes y habitualmente favorables. Sin embargo, existen algunas alianzas que resultan menos favorables para el desarrollo, aunque cumplan una función inicialmente protectora e incluso de balance temporal frente a un conflicto. Estas son las coaliciones (una alianza entre dos o más miembros en oposición directa a un tercero, generalmente oculta, involucrando a miembros de distintas generaciones) y las triangulaciones (ocupación de un lugar de balance de un miembro de la familia respecto de otros dos que se encuentran en conflicto; el "tercero triangulado" corre el riesgo de ser identificado con la función y darle un sentido vital que la rigidice).

Flexibilidad: Supone la constitución de límites externos, fronteras permeables de contacto entre la familia como unidad y el macro contexto que permiten el intercambio constante de información y, con ello, favorecen el desarrollo global del sistema familiar.

Rol: Aun cuando Minuchin no realizó una definición específica de este elemento en términos sistémicos, de su trabajo se desprende la idea de que cada miembro de una familia está llamado a ejercer unas acciones concretas dadas por su posición en el sistema y por la expresión de elementos identitarios particulares; de este modo, se constituye como rol no solo aquello que cumple una función estructural concreta (como por ejemplo "el rol parental" ejercido por los adultos en función de los pequeños y que implica, cuidado, nutrición, protección, formación, etc.), sino también aquello que le supone a cada miembro un ejercicio idiosincrático y que, a partir de ello, se constituye como función estructural: "la seria", "el niño cariñoso", "la artista de la familia", por nombrar algunos ejemplos.

La observación estructural de la familia fue planteada como un formato de evaluación que permitiera a los terapeutas orientar su actuar clínico. Como es acorde con las líneas paradigmáticas del mundo sistémico, el terapeuta que conoce a la familia la conoce en acción, introduciendo información y situándose en un rol y jerarquía definida, ofreciendo nuevos elementos interaccionales. Así, constituimos el sistema terapéutico del que participamos y que sustenta nuestro actuar (Umbarger, 1983). 
Una vez que incorporamos estos elementos que guían la observación, es indispensable integrar, no sólo los patrones de la macro cultura de la que también somos parte, sino también una lectura que cuestione nuestros ideales de funcionamiento y que permita identificar en cada unidad comportamental y vincular, las opciones que las familias toman para hacer frente a lo que viven, de acuerdo con lo que consideran posible y permitido en sus propios mandatos operativos, y a lo que les permite resguardar sus elementos identitarios (Medina, 2014). Hacemos, entonces, una mirada crítica de lo que estamos conociendo, nos disponemos a situar la información respecto de aquellos que la están viviendo y ponemos el énfasis en preguntarnos: ¿Qué objetivos se cumplen con este modo de estructurar la realidad familiar? ¿Puede ser que este esquema vincular, que tal vez yo considero negativo, tenga en esta familia un sentido de protección?

Estas preguntas, necesariamente, nos llevan a conocer las funciones específicas de las familias.

\section{Funciones de las familias: anhelos, posibilidades e identidades en desarrollo}

Tal como se mencionó en el acápite anterior, la familia es un sistema dotado de estructura que cumple, en lo general, unas funciones concretas; una interna: la protección psicosocial y desarrollo de sus miembros; y una externa: la transmisión de elementos culturales y su adecuación a las experiencias personales y vinculares. Las familias imprimen a sus miembros una identidad familiar que otorga sentido de pertenencia y permite un desarrollo cautelado, como también una identidad personal que implica la separación del núcleo de origen y permite la expresión de las particularidades, y la integración de información novedosa que conduce a la autonomía.

En el camino de vida de cada familia, podemos observar distintas funciones específicas que llevarán a la consecución de sus macro funciones ya descritas; estas funciones específicas permiten que cada persona pueda a su vez transitar su propio ciclo vital, incorporar experiencias relacionales, construirse históricamente y desarrollar un sentido de identidad (Linares, 1996). 
En la cultura occidental existen distintas configuraciones familiares. Sin embargo, existe bastante acuerdo en esperar que todas ellas ofrezcan a sus miembros condiciones de desarrollo favorables para la salud integral y la expansión de capacidades y aprendizajes. Un concepto sistémico, central en este aspecto, fue desarrollado por Juan Luis Linares (1996), denominado nutrición relacional, refiriéndose al fluir de los sentimientos amorosos que están en la base de nuestra experiencia. Para Linares, este amor es un amor complejo, un fenómeno relacional multifactorial, en el que confluyen emociones, sentimientos, elementos cognitivos y elementos pragmáticos: "Existen pues, un sentir, un pensar y un hacer amorosos que, dirigidos hacia la persona objeto de los mismos, deben ser percibidos por esta como tales." (Linares \& Soriano, 2013).

El amor complejo, aquí expuesto, sirve como base para la construcción de una personalidad madura. Siguiendo a Linares, nuestra experiencia relacional fundante es la experiencia de ser amados y, a través de ella, desciframos los códigos relacionales de la familia en la que nacemos. Esta atmósfera relacional amorosa, da paso a una segunda experiencia relacional de alta significación vital, la confirmación inicial de la identidad, el proceso en que somos reconocidos como personas diferentes de nuestros padres/ madres/cuidadores y, de ser el caso, de nuestros hermanos y hermanas. Es, a través de la experiencia de ser nombrados, atendidos en nuestras necesidades, escuchados y queridos de manera distintiva, que vamos configurando una idea de quiénes somos. Desde esta perspectiva, la nutrición emocional y la confirmación de identidad, constituyen funciones específicas que las familias están llamadas a cumplir, en pos de otorgar a sus miembros bases para la salud y el desarrollo.

Al integrar los elementos de la comprensión sistémica, podemos notar que estas funciones se cumplimentan principalmente en el subsistema parental, puntualización que no está exenta de complejidades. Dado que estas descripciones también se enmarcan en un contexto cultural específico (el europeo), es importante mantener la visión crítica y curiosa a propósito de las variabilidades de cada contexto. Nuestra Latinoamérica se ha construido, en lo socio familiar, más a la manera de un mosaico que de un trazo homogéneo (Montecino, 1991). Y es allí donde también las familias, con sus diferencias, apuntan a cumplimentar las funciones específicas que hemos mencionado. La mirada sistémica, entonces, nos permite identificar 
elementos vinculares y patrones presentes en esas múltiples y coloridas realidades (White, 2002). Veremos familias monoparentales, familias cuyos núcleos integran miembros de tres o más generaciones, familias de pocos miembros, familias que incorporan en el núcleo ramas de la familia extensa, familias que incorporan en sus núcleos a miembros no filiados biológicamente, entre otras múltiples posibilidades que amplían nuestro repertorio relacional. Estas familias se avocan, también, a ofrecer a sus miembros una adecuada nutrición relacional, a confirmar sus identidades, a protegerles y a transmitirles las normas de la cultura de la que forman parte; cada una a su propio ritmo, graduación y forma, sirviéndose de sus posibilidades comunicacionales.

Y... ¿Cómo conocemos esas posibilidades comunicacionales?

\section{Comunicación humana, mensajes en las familias: la transmisión infinita}

Hemos visualizado al sistema familiar como una entidad dotada de cierta estructura, constituida por ciertos elementos participantes de intercambios y que cumple determinadas funciones generales y específicas. Mención especial merece, entonces, uno de los componentes funcionales más relevantes en la comprensión sistémica: la comunicación, definida como: "el conjunto de elementos en constante interacción en la que toda modificación de uno de ellos afecta las relaciones entre los otros elementos" (Marc \& Picard, 1992). Entendemos, entonces, a la comunicación humana como el intercambio constante de información, intencionada o no, que sucede a propósito de la existencia misma (Watzlawick, Bavelas, $\&$ Jackson, 1991). Desde allí, que se realice una homologación práctica entre comunicación y conducta para mostrarnos el flujo ininterrumpido de información que, en la experiencia, será dotada de significado y utilidad.

Con todo, en la mirada de Watzlawick et al. (op.cit. 1991), la comunicación humana puede observarse de modo estructural, es decir, podemos distinguir unidades comunicacionales específicas, a diferentes niveles. Llamaremos mensaje a una unidad comunicacional singular, posee un contenido y se define en una relación concreta; la transmisión de la información puede estar intencionada o no. Llamaremos interacción a una serie de mensajes intercambiados entre personas, y llamaremos pauta interaccional al nivel mayor de complejidad en que se identifican elementos 
estables en las secuencias de comunicación, que se activan de manera similar en diferentes momentos y situaciones. Una pauta interaccional implica elementos de significado, de estructura de la relación, de los roles que ejercen los participantes en el sistema vincular y de la conducta que se ejercerá respecto de otras relaciones. Esta mirada compleja de la comunicación permite identificar en nuestras relaciones, además de una serie de mensajes que circulan permanentemente, unos elementos que se transmiten de manera distintiva en las familias: las mitologías.

Para comprender el concepto de mitología familiar, es necesario primero definir sus unidades constituyentes. De acuerdo con Linares (1996), la principal unidad de contenido que sostiene información compleja y multidimensional en la vida relacional es la narración; una serie de contenidos respecto de quiénes somos, lo que hacemos, lo que queremos/ podemos hacer, lo que constituye la vida, etc. que poseen una coherencia funcional. Las narraciones encuentran en la vida familiar una existencia recursiva: se construyen a partir de lo que se recibe en ella y, a la vez, se reconstruyen con los elementos que cada miembro incorpora a propósito de su experiencia particular. Para este mismo autor, las narraciones pueden constituir a su vez narrativas, cuando se estructuran como unidades complejas en las que los contenidos se agrupan temática y formalmente; y ofrecen, además, información de proceso. En términos coloquiales, las narrativas no solo nos muestran qué es lo que alguien piensa, siente o hace; también nos dicen cómo llegó a esa conclusión y en qué zona de la experiencia de esa persona se ubican esos pensamientos, sentimientos y acciones.

Las mitologías, por su parte, están constituidas por información familiar diversa. Se distinguen de los recuerdos o de la historia familiar, por cuanto transmiten información acerca de cómo debemos estar en el mundo con base en nuestra participación en esta familia en específico, sin por ello transformarse en órdenes directas y teniendo aún más poder que ellas. Las mitologías familiares constituyen un espacio consensuado en el que confluyen las distintas narrativas de los miembros, las que, a su vez, permiten la expresión de diferentes narraciones en constante construcción. En palabras de Linares (1996), "las narraciones participan de un sustrato emocional común, así como de un mismo troquelado epistemológico y de una verificación pragmática mutuamente coherente, pero conservan 
también una suficiente autonomía para poder desarrollarse con cierta independencia”. De esta definición, podemos comprender, además, que las mitologías familiares tienen un gran poder orientador de nuestro desarrollo, pero pueden ser lo bastante flexibles como para permitir el intercambio de información con el extra sistema y enriquecer el curso vital de los miembros. El tejido narrativo familiar es una muestra, bastante concreta, de un elemento central de la vida humana: la danza constante entre estabilidad y cambio (Watzlawick, Weakland, \& Fish, 1974).

Las mitologías familiares implican también la transmisión de valores culturales, formas de hacer de acuerdo con la edad, el género, la posición en el entramado social, etc. Esta transmisión ideológica ocurre constantemente; mostramos estos contenidos en lo que decimos y hacemos, en el modo en que expresamos nuestros sentimientos. Aquello que nos es permitido vivir en cada familia se sostiene en la mitología y, desde ella, establece posibilidades: tener hijos, estudiar una carrera profesional, cuidar de los pequeños en casa, hablar de lo que sentimos, abrazar a los demás o decidir sobre gustos personales, son ejemplos de aquello que cada familia permite, modela o limita a sus miembros, y que se expresa tanto en discurso directo como en las manifestaciones de opinión subsecuentes a eventos cotidianos específicos. En otras palabras, construimos una idea de cómo funciona el mundo por lo que vemos, lo que escuchamos, y también por lo que no, por lo que se critica, lo que se valora, lo que se ensalza o invisibiliza en todas las interacciones de la vida familiar, interacciones que pueden constituirse como una pauta y, a partir de ello, como una definición de realidad.

\section{La red social: estableciendo membranas del sistema en los sistemas}

Tal como lo mencionáramos al inicio de este capítulo, la comprensión sistémica de la vida humana es, en realidad, una aplicación específica de la comprensión general sistémica, tanto del mundo vivo como de las creaciones materiales, que como humanidad hemos desarrollado. Desde esta mirada, ocurre que podemos identificar las propiedades generales de todo sistema en cualquier corte de la realidad que hacemos: Estamos, constantemente, visualizando patrones, esquemas comunicacionales, pautas interaccionales, roles y funciones; anteojos que nos permiten comprender la complejidad de las realidades de las que somos parte. Así, entonces, resulta imposible 
imaginar una comprensión sistémica de la experiencia humana si no dirigimos nuestra mirada, también, al nivel macro sistémico en el que cada familia está inserta y con el que interactúa.

Ejercitando nuestra capacidad de reducir temporalmente la complejidad en la observación, podemos iniciar esta mirada del sistema en el sistema definiendo un primer nivel de interacción multi nivel. Hablaremos de la red social personal o significativa, recordando la propuesta original de Gregory Bateson acerca de la necesidad de realizar un trazado de las fronteras de lo individual que considere las interacciones significativas de la persona y que contribuirán a su construcción (Sluzki, 1997). La red social personal o micro red es una porción del entramado social en el que situamos a una persona en el centro y establecemos, a propósito de sus significaciones y experiencias, los vínculos que resultan tener un mayor impacto afectivo e intimidad. Desde ahí, podemos distanciarnos progresivamente de ese centro para establecer diferentes vínculos, con decreciente nivel de intimidad e intensidad, hasta alcanzar las fronteras de la red social más grande. La macro red social incluye la comunidad de la que formamos parte, nuestra sociedad, sus aspectos institucionales y políticos, la organización cultural, los elementos propios de nuestra especie y nuestra ecología.

La red social personal, puede también definirse en términos estructurales. Siguiendo a Sluzki (op.cit. 1997) estas características son:

- Tamaño: Dado por la cantidad de personas identificadas como partes de la red.

- Densidad: Es decir, conexión entre miembros con independencia de la persona central. Las densidades altas en ciertas zonas de la red social personal, favorecen el cotejamiento de información respecto de la visión y estado de la persona central y la capacidad de tomar acciones conjuntas. Sin embargo, una red social personal solo de alta densidad, reduce las posibilidades de crecimiento y enriquecimiento de los miembros, y favorece la rigidez comportamental.

- Composición/Distribución: Se relaciona con el nivel de cercanía entre la persona central y los miembros de su red social personal, si bien es muy importante que existan personas muy cercanas 
en intensidad e intimidad; el desarrollo se favorece si también tenemos personas significativas en el ámbito de las amistades, el trabajo y la comunidad.

- Dispersión: También llamada accesibilidad, se refiere a la distancia geográfica entre la persona central y los miembros significativos de su red social personal. A propósito de la tecnología, actualmente, observamos esta variable, no solo desde el elemento geográfico concreto, sino también desde las posibilidades de contacto y soporte factibles de obtener a través de medios de comunicación a distancia (teléfono, mensajerías instantáneas, etc.)

- Homogeneidad/Heterogeneidad: Variabilidades presentes en los miembros de la red, a propósito de factores como edad, género, pertenencias culturales, etc.

- Atributos de Vínculo Específico: Tales como compromiso, carga de la relación, historia común, durabilidad e intensidad.

- Funciones: Hasta ahora, identificamos la compañía social, apoyo emocional, guía cognitiva y consejo, regulación social, ayuda material y de servicios, y acceso a nuevos contactos.

Al realizar esta mirada de las interacciones, vamos imaginando cómo estos conceptos se constituyen como experiencias concretas que identificamos en nuestra propia vida: amigos íntimos, "compañeros de aventuras", agradables compañeros de estudio o trabajo, personas conocidas a las que recurrimos por sus saberes específicos, entre otros muchos nombres que damos a los distintos componentes y niveles de nuestra red social personal, y a través de los cuales la construimos como una realidad. Lo que somos, en relación con otros, puede verse fortalecido o perjudicado a propósito de la estructura de nuestra red y el formato de nuestros vínculos; así como en la familia, nuestro "ser en red" puede tener mucho poder y nuestra esperanza y trabajo se orienta a la construcción y reconstrucción de esquemas vinculares respetuosos, saludables y potenciadores del crecimiento y el desarrollo.

Mas, como hemos visto, nuestras múltiples realidades no parecen limitarse a las personas que conocemos; tampoco a quienes identificamos como una influencia aceptada, sino que se extienden a propósito de las posibilidades interaccionales y la construcción de diferentes hechos 
sociales que se incorporan en la vida humana, a propósito de las prácticas narrativas cotidianas. Así como hemos definido las narrativas personales y familiares, es momento de poner el foco en los elementos macro sociales que en ellas aparecen. Dados los patrones culturales que son más aceptados en cada sociedad, existirá una interacción simbólica entre la persona y el entorno social, proceso interpsíquico del cual emergen los componentes de la narrativa de sí mismo y que se manifestarán como un modo específico de estar en el mundo (Medina, 2014).

Llamaremos discurso cultural saturado a aquellas "verdades normalizadoras que configuran nuestras vidas y nuestras relaciones" (White $\&$ Epston, 1993). Estas premisas, tomadas como verdad en cada entramado cultural específico, configuran un marco socio discursivo que tiene códigos morales y reglas, y que, muchas veces, contiene explicaciones acerca del sufrimiento y delimita las posibilidades de cambio (Medina, 2014).

En nuestra Latinoamérica, existen diversas premisas que componen el discurso cultural saturado y que es necesario conocer para establecer sus posibilidades y necesidad de ser deconstruido. Así como valoramos nuestra tendencia al apoyo social y al conocimiento del otro, lamentamos esta suerte de doble moral en la que estamos insertos y que favorece nuestra inmovilidad respecto de alcanzar niveles de bienestar óptimos de manera colectiva. En palabras de Medina (2014), el mosaico discursivo latinoamericano parece confluir en una sensación de limitación y queja, en la que las prácticas habituales de cooperación y solidaridad se extienden cotidianamente sin alcanzar la potencia de un discurso de corresponsabilidad y proactividad social, que nos impacte en términos de identidad y que favorezca la constitución de un sí mismo cultural responsable y agente (Spears, 1997).

Vivimos en un continente que combina, amalgama y abigarra diferentes experiencias y estilos, identidades e historias; continente muchas veces azotado por los embates de una naturaleza fiera, y perdido en sus relaciones con otros continentes, a propósito de sus recursos naturales. Nuestro discurso cultural saturado parece, actualmente, limitar nuestro reconocimiento de todo aquello en lo que respondemos con adaptación y resiliencia, impidiendo que nos hagamos conscientes de nuestros recursos y fortalezas, de nuestros lazos y narrativas constructoras. Si hemos de trabajar por la salud y el bienestar, los terapeutas no nos limitaremos a un foco vincular específico, sino que consideraremos siempre los factores 
macro sociales y habremos de tomar postura respecto a la influencia de esos factores en nuestro modo de vivir.

\section{Sistemas y vulnerabilidades: la frágil fortaleza de nuestro ser en red}

"Cada día tiene una historia que merece ser contada, porque estamos hechos de historias. Es decir, los científicos dicen que los seres humanos están hechos de átomos, pero un pajarito me dijo que también estamos hechos de historias."

(Eduardo Galeano, Festival Internacional "Voces del Mundo" de PEN. Nueva York, USA. Mayo 2013).

Teniendo a la vista, entonces, los componentes básicos de una comprensión sistémica recursiva, que avanza en complejidad y que incorpora elementos de distintos niveles de realidad, nos acercamos a entender cómo emerge el sufrimiento, la enfermedad, el daño, qué combinaciones de elementos favorecen su aparición y qué factores permiten hacerle frente.

Nos preguntan por las vulnerabilidades observables desde la perspectiva sistémica $y$, necesariamente, tenemos que focalizar nuestra mirada en una porción específica de la realidad. Sin embargo, podemos imaginarnos que existe, en todos los componentes que revisamos, una suerte de factor común que soporta gran poder a la hora de conocer nuestras posibilidades: La narrativa de cómo somos, construida en los distintos niveles de la experiencia relacional.

Como vimos al inicio, las narrativas se expresan en todo lo que decimos y lo que hacemos. A continuación, presentaremos unos fragmentos de sesiones clínicas que ilustrarán los diferentes niveles de observación que la mirada sistémica nos provee.

\section{"Ser mujer - ser hombre": la cotidianeidad de nuestras posibilidades}

(Fragmento de caso 1)

Terapeuta: "Entonces, ¿no te has podido concentrar en el colegio, Miguel? La mamá acaba de decir que antes te iba muy bien y ahora te nota diferente... ¿tú te notas diferente? 
Miguel: (mirando a su madre) "Yo ya no soy tan chico como antes, cumplí nueve hace tres semanas... y yo no tengo que hacer tantas cosas en el colegio"

Ana: (madre de Miguel) "Últimamente repite eso, de que no es chico, yo no sé bien por qué, en casa tiene todo para que le vaya bien... yo me esfuerzo mucho y su papá también, pero él no responde" (llora).

Miguel: (a su madre) "¡Lo que pasa es que tú tienes un problema! Vea como llora siempre (a la terapeuta), pero yo no soy tan chico y me doy cuenta. Todos los días están gritándose y mi papá siempre le grita puros garabatos*, ellos creen que yo no entiendo lo que pasa, pero lo entiendo mejor que ellos... Yo sé lo que mi mamá tiene que hacer"

Madre: (a la terapeuta) "Usted comprende que lo hago por él, tiene que tener una familia para que le vaya bien."

Terapeuta: “QQué entiendes, Miguel? ¿Qué crees que tiene que hacer la mamá?

Miguel: "Tiene que separarse de mi papá, nosotros podemos salir adelante, no tenemos que aguantar eso, que nos maltrate, yo sé que eso es violencia, aunque no lo quieran decir".

Madre: (llorando, mirando a la terapeuta) "una cree que no lo saben, nunca discutimos delante de él porque mi marido siempre llega tarde; no pasa mucho tiempo con nosotros... Yo no sabía que él sabía... me siento mal y bien en este momento (llora) no sé qué hacer... ¿usted cree que en verdad podemos salir adelante nosotros? Igual Miguel parece fuerte ¿Verdad?, él es hombre también, y es bien correcto... siempre está conmigo, tal vez podamos lograrlo".

Parece necesario situarnos, nuevamente, al comienzo, para caminar ahora la lectura sistémica con los anteojos de la vulnerabilidad. Miguel representa a miles de hijos que, lamentablemente, crecen en familias en las que se ejerce violencia de género. A propósito de esta escena, vemos como en el contexto de la violencia, la pareja de padres no puede establecerse como un subsistema definido que dé soporte y estabilidad tanto a sus miembros como al hijo, lo que genera una alianza trianguladora entre la madre y Miguel; el niño se alía a la madre sintiendo que tiene que salir en su defensa y que esa defensa permitirá mejorar la situación de ambos; los límites 
difusos no permiten a Miguel comportarse como un hijo y preocuparse de asuntos relativos a su edad como el colegio y los amigos. Las declaraciones de ambos pueden resultarnos atentas y cariñosas y, por cierto, lo son; con todo, es preciso que veamos el modo en que transmiten además, las ideas que cada uno tiene acerca de quién es y de sus posibilidades: la fragilidad de las mujeres, la dependencia de figuras masculinas, la carga a los varones de establecer la única defensa de la familia, la sensación de desamparo ante la autonomía, contenidos que aparecen aquí como narrativas identitarias, que se reconfiguran luego como mitología familiar y que, desde ese lugar, orientan la mirada de los miembros de la familia en busca de mantener una configuración conocida (un varón fuerte y defensor respecto del mundo externo; una mujer cuidadosa ocupada del mundo íntimo) aunque no se dé en la pareja de padres. La parentalidad deteriorada (Linares, 1996) implica en este caso una ruptura de la ordenación jerárquica de la familia y una modificación limitante en el ejercicio de los roles en la que vemos a una mujer que no cree en sus propias capacidades de establecerse y a un niño que carga con la responsabilidad de defender a su madre de un padre violento.

Imaginemos, además, el contexto de esta familia, condiciones de precariedad económica y educacional que limitan una visión esperanzadora del presente y del futuro y que, seguramente, limitan también la mirada de los propios recursos y posibilidades.

Ahora bien, ¿debemos tomar estos factores como una prognosis lapidaria acerca de la vida de esta familia? ¿Es que, a partir de esto, no hay oportunidad de vivir mejor, con menos violencia y constituyendo una nueva organización familiar?

Nos disponemos a visualizar ahora el modo en que, a partir de nuestras condiciones familiares y personales, utilizamos lo que tenemos a mano para construir una vida en que se pueda tener bienestar y crecer, a la vez que cuestionamos incluso nuestras premisas iniciales acerca de los factores que hacen que pensemos en los riesgos al desarrollo ¿Qué elementos nos permitirían movilizar la actual organización de esta familia? ¿Hay algo, en lo narrado por estas personas, que nos permita imaginar una relación distinta? 
Ya en la escena descrita podemos visualizar recursos favorables que han permitido a esta familia hacer frente a la adversidad; para identificarlos, es necesario conectarnos con las posibilidades, ponernos el anteojo de los recursos, plantearnos, por ejemplo, que el hecho mismo de que hayan llegado a consultar es un recurso; a propósito de un tema que se considera importante (el rendimiento escolar) y manejable (la madre puede accionar para intervenirlo: va a colegio, consulta en el hospital local), la familia acepta una conversación abierta, la madre se muestra competente y activa frente a este tema, unidad comportamental que podemos tomar y amplificar, es decir, buscar en la historia otras experiencias en que se repita esta muestra de acción y competencia materna para constituir una nueva narración acerca de la capacidad de la madre y movilizar estrategias de ensayo para aplicarla en escenarios nuevos. A este ejercicio le llamamos identificación de narraciones alternativas, que, si bien no necesariamente van a constituirse como una narración dominante en la persona, significan la activación de posibilidades hasta ahora no intentadas. Paradójicamente, tenemos el desafío de buscar "vulnerabilidades a las vulnerabilidades" para proponer un nuevo color en la dinámica familiar.

Y ¿Miguel? Este niño de nueve años nos muestra un movimiento humano maravilloso, al dejar de rendir en el colegio, su organismo es capaz de dejar por un momento el lugar de un hijo fuerte, muestra un comportamiento del que la madre sí se puede hacer cargo y, sin planearlo, la moviliza como adulta, activa partes del subsistema parental y se permite una acción inesperada que también abre la posibilidad de incorporar narraciones nuevas: hay algo que no puede hacer, algo para lo que sí necesita ayuda. Esta línea narrativa nos permite ver a un niño pequeño que no necesariamente crecerá cargando el peso del mundo sobre sus hombros, que se ha permitido recibir ayuda y ser acogido; aquí también tenemos oportunidad de trabajar amplificando este tejido y poniéndolo siempre en relación con otros, conjugarlo con la conducta de la madre para enhebrar ambas narraciones como base en una narrativa nueva, en la que la madre es competente, puede acoger a su hijo, muestra fortaleza mientras el hijo se vuelve capaz de distinguir lo que puede y lo que no, lo que le corresponde hacer. Podemos, además, incorporar aquí un cuestionamiento al componente de género presente en la mitología familiar ("la mujer frágil", "el hombrecito de la casa") y plantear un enhebrado 
social ("la fuerza de la mujer latinoamericana", "el hombre que puede pedir ayuda y reconocer lo que siente"), sin necesidad de ofrecer un discurso armado, sino sólo utilizando las unidades comportamentales que tenemos, validándolas para darles más atención y significado, tomando aquellas que generan sufrimiento en una relación de acogida y aceptación que suponga una toma de decisiones progresiva.

\section{"No hay amor más grande": el sacrificio que mantiene a las familias.}

(Fragmento de caso 2)

Terapeuta: “¿Cómo llegas esta semana Sebastián? Estuvimos en la sesión pasada conociendo un poco de la relación con tus padres y veíamos que hay mucho que contar..."

Sebastián: "Sí... mmmmmm.... No me gusta tanto hablar de eso en realidad, sobre todo de mi papá... Igual, ¿te puedo decir algo? Es que él es como extraño, cuando yo era más chico, él les prestaba atención a mis hermanas nada más, a mí como que no me quería, no me miraba mucho, siempre encontraba que yo hacía cosas malas, que era tonto... tal vez por eso y quiero tanto a mi mamá, ella siempre está conmigo y es como una santa porque cada vez que yo quedo mal ella me recibe"

Terapeuta: " $i T e$ refieres a cuando bebes demasiado? (consultante asiente con la cabeza)... Entonces ella te recibe en casa y te cuida... iY el papá se enoja por eso?"

Sebastián: "Claro! Siempre pelean cuando pasa eso... yo a veces pienso que un día mi mamá le va a parar los carros*, porque él no es mucho aporte, no la conoce tampoco a ella, nunca la escucha. Cuando yo era chico mi mamá siempre estaba sintiéndose sola y me contaba a mí todo lo que él le decía, claro, nunca la golpeó, a nosotros tampoco, pero siempre estaba buscando trabajos lejos y el poco tiempo que pasaba en la casa no hablaba a menos que fuera para criticarnos a mi mamá y a mí. Claro, mis hermanas mayores eran como sus princesas, mi mamá tampoco las quiere tanto porque dice que él las prefiere, me elige a mí porque ya la acompaño y la escucho siempre... bueno, y ella también me recibe siempre, aunque esta familia es de cinco personas, es como si fuésemos dos no más.' 
Terapeuta: Y tus hermanas ¿qué hacen cuando llegas borracho a casa?

Sebastián: ¡Pff! Me critican también, pero ayudan un poco a mi mamá... no por mí, a ella como que le tienen pena, entonces la retan* y le dicen todo el tiempo que no me reciba más, que ellas igual están cansadas... y no sé de qué están cansadas, ellas pudieron entrar a estudiar, eso es fácil, más como ellas que se han demorado años... igual mi mamá siempre dice que tenemos que estar unidos y por eso ella nos apoya a los tres al final, pero yo sé que a mí sí me quiere."

En las familias en las que se presenta consumo problemático de sustancias, resulta sencillo al mundo clínico focalizar en la sustancia y sus efectos sindromáticos. Reconociendo, por supuesto, la necesidad de atender igualmente a estas circunstancias, aquí tomaremos nuestros conceptos sistémicos para identificar los factores de vulnerabilidad que sujetan la situación.

Hemos ya definido que las mitologías familiares sostienen el modo de vivir de cada familia. En este caso visualizamos los primeros elementos fundantes de esas mitologías: Linares (1996) llama conyugalidad disarmónica al vínculo de pareja que presenta poca sustancia en cuanto a los contenidos (conocerse, sentir cariño y respeto por el otro, considerarlo un compañero, etc.), pero que se constituye como un vínculo del cual no se puede prescindir. En el fragmento vemos que los padres de Sebastián viven esta conyugalidad deteriorada y que, a partir de ella, se ha generado una triangulación desconfirmatoria en la que Sebastián y su madre están aliados "en contra" del padre. Sebastián se levanta como el paño de lágrimas de una madre que le ofrece protección y una pseudoconfirmación (su identidad es reconocida sólo por cuanto está al lado de la madre en esta alianza) y a través de esa pseudoconfirmación encuentra un rol que ejercer. Podemos imaginar que las críticas tempranas del padre limitan el desarrollo de Sebastián, quien se construye a sí mismo en torno a la madre; a sus 20 años no se imagina viviendo solo ni teniendo un trabajo estable. Sin embargo, vemos que, al parecer, los tres hijos tienen dificultades para visualizarse como adultos, las hermanas de Sebastián "se han tomado muchos años" para terminar sus estudios superiores, lo que también retrasa su posibilidad de iniciar el camino autónomo. Sería fácil pensar que lo hacen para utilizar sus privilegios, mas la mitología familiar parece indicar que la autonomía de los hijos dejaría a una madre abandonada y sola. 
En este escenario, visualizamos que el consumo de alcohol de Sebastián parece favorecer una sensación de control en la madre, las posibilidades del padre de mantenerse menos involucrado en la crianza y la dilación en la independencia de las hermanas. Desde esta perspectiva, ante la mitología de la unión familiar en cualquier circunstancia, el comportamiento de consumo de Sebastián parece permitir que estos roles se mantengan como los hemos visto y no se avance a la etapa de individuación de los hijos y experiencia de "nido vacío" por parte de los padres. A esta situación la llamamos funcionalidad del síntoma, y nos permite visualizar distintas porciones comportamentales en la dinámica familiar que confluyen para el logro de cierto objetivo del sistema. Podemos plantearnos, desde aquí, que esta familia no parece conocer una forma de estar unida que no esté situada en "el problema de Sebastián", de pequeño el rendimiento escolar, de joven el consumo problemático de alcohol y, en todos los momentos, la simbiosis con la madre. Las hijas mayores encuentran aquí, también, una manera de validarse frente a la madre, sin perder el lugar de poder que el padre les ha construido: la asisten respecto al cuidado crítico de Sebastián, aleccionándola en el proceso, mientras el padre puede permitirse no estar involucrado en la búsqueda de estrategias de contención y afrontamiento, y mantenerse en la periferia del sistema familiar. ¿Vemos ahora a otro Sebastián?

Muchas veces, al conocer inicialmente situaciones familiares como esta, puede surgir nuestro impulso normalizador: querríamos que Sebastián tuviese un trabajo, que sus hermanas terminaran sus carreras, que lo padres se avengan y que los hijos se independicen. Antes de llegar a dialogar a la planicie en que habitan esos objetivos, parece necesario mirar a nuestro consultante con los anteojos de los recursos: ¿Cuánta fortaleza se requiere para mantener unida a esta familia? ¿Cuánto de sacrificio tiene? Nuestro consultante parece ahora un hombre joven y fuerte que parece estar haciendo una demostración profunda de amor a costa de su propio desarrollo. ¿Habrá otras maneras de amar? Recordemos también que, clínicamente, llamamos "Dependencia" a estas relaciones problemáticas con las sustancias. Entonces ¿quiénes son los dependientes? ¿De qué están dependiendo? ¿Podrá esta familia vencer el miedo a la destrucción y mantenerse en la interdependencia de sus miembros, más que en la dependencia? 
La mirada relacional nos invita a buscar estos recursos, a enfrentar estos miedos poniéndolos sobre la mesa y trabajando respecto de ellos. Nos invita a rescatar este amor y esta fortaleza y buscar las posibilidades que tiene de expresarse de maneras menos destructivas. Desde aquí, nuestro objetivo no es el trabajo o la abstinencia; es la reconexión con la propia vida poniendo estas capacidades en otras relaciones, reconfigurando las que existen para darles flexibilidad y posibilidades de crecimiento. Al trabajar con la familia resulta posible resaltar, por ejemplo, esta capacidad de respuesta, de "no abandonar a los caídos", aunque no estemos de acuerdo con sus decisiones; si estos valores se aseguran, probablemente no necesitarán ser puestos a prueba de modo tan crítico constantemente.

\section{Cerrar para abrir: el constante movimiento de las temporales conclusiones sistémicas}

Hemos realizado un breve recorrido por la conceptualización sistémica básica y, con ella, hemos visitado algunas escenas familiares que nos muestran, entre otras cosas, la paradoja de la salud y de la intervención clínica. Nuestra vida perece estar en permanente movimiento y, a propósito de ese movimiento, integrar una gran diversidad de factores, de lecturas, de emociones, pensamientos y comportamientos que van reconstruyéndose constantemente. Si el movimiento no se detiene, y cada sistema lo regula para lograr permanecer mientras crece, parece lógico, entonces, asumir que leeremos las condiciones actuales de modo abierto y flexible. Hemos declarado que cada sistema danza entre la información que posee y la que recibe, permanece y cambia, busca equilibrio y reconstrucción. ¿Qué sentido tiene entonces, la mirada preventiva o la intervención clínica?

Parece importante hacernos responsables de construir códigos relacionales, narrativas y mitologías que favorezcan la salud y el crecimiento, que podamos hacer y favorecer el ejercicio de una confirmación genuina de la identidad temprana y de una nutrición emocional adecuada, no descalificando los intentos que todos hacemos por estar vivos y sentirnos acompañados, sino comprendiendo que nuestra realidad inicial no determina nuestras posibilidades. Aunque las condiciones socio culturales y familiares limiten la experiencia, desde el mundo de la psicología, particularmente desde el mundo de la psicoterapia, tenemos la tarea de movilizar información adecuada, solidaria, respetuosa en todos los niveles, 
que permita disponer de elementos con los que construir nuevas relaciones. Nuestra experiencia en familia puede dañarnos; el modo en que nos han criado puede parecernos "loco", incluso en algunos casos "terrible" y, probablemente, acertemos en que hay cosas que consideramos negativas y que buscaremos no repetir. Con todo, la vulnerabilidad en sí misma constituye una paradoja también: "Es verdad que el junco se dobla ante la presencia de cualquier brisa y es verdad también que cuando llega la tormenta, su capacidad de doblarse lo mantiene en su raíz."

\section{Referencias}

Bateson, G. (1969) "Mente/Ambiente" conferencia reproducida en: Una unidad sagrada. Pasos ulteriores hacia una ecología de la mente (traducción de Marcelo Pakman). Barcelona, España: Gedisa.

Galeano, E. (2013, mayo 8). Eduardo Galeano habla sobre su nuevo libro, "Los hijos de los días". Recuperado de: https://www.democracynow. org/es/2013/5/8/eduardo_galeano_chronicler_of_latin_americas

Linares, J.L. (1996) Identidad y Narrativa. La terapia familiar en la práctica sistémica. Barcelona, España: Paidós Ibérica.

Linares, J. L., \& Soriano, J. A. (2013). Pasos para una psicopatología relacional. Revista mexicana de investigación en psicología, 5(2), 119146. Recuperado de: http://www.medigraphic.com/pdfs/revmexinvpsi/mip-2013/mip132b.pdf

Marc, E., \& Picard, D. (1992) La interacción social: cultura, instituciones y comunicación. Barcelona, España: Paidós.

Medina, R. (2014). Deconstruyendo el "sí mismo farsante" y el "sí mismo autocompasivo". Nuevos aportes a la terapia familiar crítica. En Medina, R., Laso, E., \& Hernández, E. (coords.) Pensamiento Sistémico. Nuevas perspectivas y contextos de intervención. Ciudad de México, México: Litteris.

Minuchin, S. (1977) Familia y Terapia familiar. Barcelona, España: Gedisa. Montecino, S. (1991) Madres y huachos: alegorías del mestizaje chileno. Santiago, Chile: Cuarto Propio.

Sluzki, C. (1997) La red social: frontera de la práctica sistémica. Barcelona, España: Gedisa. 
Spears, R. (1997) “Introduction”. En Ibáñez, T., \& Iñiguez, L. (eds.) Critical Social Psychology. London, England: Sage.

Umbarger, C. C. (1983). Structural family therapy. New York: Grune \& Stratton.

Watzlawick, P., Weakland, J., \& Fish, R. (1974) Change: Principles of Problem Formation and Problem Resolution. New York: W. W. Norton Company.

Watzlawick, P., Bavelas J. B., \& Jackson D. D. (1991) Teoría de la comunicación humana. Interacciones, patologías y paradojas. Barcelona, España: Editorial Herder

White, M. (2002) El enfoque narrativo en la experiencia de los terapeutas. Barcelona, España: Gedisa.

White M., \& Epston, D. (1993) Medios Narrativos para fines terapéuticos. Barcelona, España: Paidós. 